\title{
ANALISIS PERKUATAN STRUKTUR GEDUNG PASCA KEBAKARAN DENGAN PENAMBAHAN PROFIL SIKU SEBAGAI PERKUATAN STRUKTUR BALOK
}

\author{
Yanisfa Septiarsilia ${ }^{1}$, Jaka Propika ${ }^{2}$ \\ ${ }^{1}$ Teknik Sipil, Fakultas Teknik Sipil dan Perencanaan, Institut Teknologi Adhi Tama, Surabaya \\ ${ }^{2}$ Teknik Sipil, Fakultas Teknik Sipil dan Perencanaan, Institut Teknologi Adhi Tama, Surabaya \\ E-mail: yanisfa.septi@gmail.com,jakapropika@gmail.com.
}

\begin{abstract}
ABSTRAK: Beton yang mengalami kebakaran pada suhu diatas $200^{\circ} \mathrm{C}$ dapat menyebabkan mutu beton mengalami penurunan, sehingga mengakibatkan penurunan kekuatan struktur. Masalah ini dapat diselesaikan dengan perkuatan struktur yaitu dengan penambahan profil untuk perkuatan struktur balok pasca kebakaran. Penelitian ini bertujuan untuk menganalisis peningkatan kekuatan struktur balok pasca kebakaran dengan penambahan profil siku. Hasil analisis yang dilakukan bahwa nilai momen nominal balok pasca kebakaran pada suhu $900^{\circ} \mathrm{C}$ dengan durasi 3 jam pada beton dan 2 jam pada baja tulangan sebelum penambahan profil siku menunjukan nilai momen nominal $\mathrm{Mn}=7161,7 \mathrm{Kg} \cdot \mathrm{m} \mathrm{Mu}=8231 \mathrm{~kg} \cdot \mathrm{m}$ pada balok 1 (ekterior) dan $\mathrm{Mn}=7891,8 \mathrm{Kg} \cdot \mathrm{m} \mathrm{Mu}=$ 8096,41 kg.m pada balok 1 (interior). Setelah penambahan profil siku dengan dimensi profil L65x65x7 pada balok pasca kebakaran menunjukan nilai momen nominal mengalami kenaikan dengan $\mathrm{Mn}=24927,03 \mathrm{~kg} \cdot \mathrm{m} \mathrm{Mu}=8096,41 . \mathrm{kg} \cdot \mathrm{m}$ pada balok 1 (interior) dan $\mathrm{Mn}=16449,5 \mathrm{~kg} \cdot \mathrm{m} \quad \mathrm{Mu}=8231 \mathrm{~kg} \cdot \mathrm{m}$ pada balok 1 (eksterior).
\end{abstract}

Kata Kunci : Kebakaran, Penurunan, Beton dan Baja Tulangan Perkuatan, Profil Siku

\section{PENDAHULUAN}

Indonesia merupakan negara dengan jumlah penduduk terbanyak keempat di dunia dengan jumlah penduduk kurang lebih 250 juta jiwa dan akan terus bertambah setiap tahunnya. Hal ini menyebabkan meningkatnya kebutuhan akan pembangunan seperti: perumahan, gedung, ruko, gudang, dan lain-lain. Pembangunan yang dilaksanakan harus mengacu pada peraturan yang ada apabila terjadi bencana alam, bangunan tersebut masih mampu berdiri dengan tegak. Material yang sering digunakan pada kontruksi di Indonesia adalah beton karena mamiliki ketahanan terhadap api, sehingga sangat cocok digunakan pada daerah tropis yang rawan terhadap kebakaran.

Akhir-akhir ini kasus kebakaran gedung di Indonesia mendapat perhatian khusus dari berbagai kalangan. Kerugian yang diakibatkan oleh bencana kebakaran yaitu harta yang habis terbakar dan trauma yang mendalam bagi korban kebakaran karena kehilangan sanak saudaranya. Selain itu, bencana kebakaran juga mempengaruhi kekuatan struktur dari bangunaan tersebut walaupun bangunan itu masih berdiri. Banyak rumah atau gedung yang terbengkalai setelah kebakaran dan bahkan harus dibongkar total karena takut bangunan tersebut kekuatan strukturnya tidak mampu menahan beban hidup maupun beban sendirinya. Maka perlu dilakukan peninjauan pada gedung pasca kebakaran yang masih berdiri.

Mengadopsi dari penelitian terdahulu peneliti ingin melakukan penelitian dengan judul "Analisis Perkuatan Struktur Gedung Pasca Kebakaran dengan Penambahan Profil Siku Sebagai Perkuatan Struktur Balok" dengan harapan penelitian ini bisa berguna bagi banyak orang.Tujuan dari penelitian ini untuk mendapatkan nilai momen kapasitas sisa struktur pasca kebakaran dan mengatahui besarnya momen struktur balok pasca kebakaran setelah penambahan profil siku untuk perkuatannya.

Beton merupakan material yang memiliki ketahanan terhadap api dibandingkan dengan material lain. Hal ini disebabkan karena beton memiliki daya hantar panas yang rendah, sehingga dapat menghalangi panas masuk kedalam struktur beton. Menurut
Priyosulistyo (2002) mengatakan bahwa pada temperatur dibawah $200^{\circ} \mathrm{C}$ beton akan mengalami peningkatan kuat tekan beton. Penurunan kekuatan lentur dan geser berturut-turut berkisar $10 \%$ sampai $20 \%$ pada saat balok beton bertulang menerima temperatur $200^{\circ} \mathrm{C}$ sampai $400^{\circ} \mathrm{C}$.

Menurut Bayuasri T, dkk (2006) penurunan kuat tekan dipengaruhi oleh temperature dan durasi pembakaran yang bervariasi sesuai pada Tabel 1 .

Tabel 1. Prosentasi Kekuatan Sisa Mutu Beton (Bayuasri T, dkk . 2006)

\begin{tabular}{|c|c|c|c|c|c|c|}
\hline \multirow{3}{*}{ Waktu } & \multicolumn{6}{|l|}{ Suhu } \\
\hline & \multicolumn{2}{|l|}{$300^{\circ} \mathrm{C}$} & \multicolumn{2}{|l|}{$600^{\circ} \mathrm{C}$} & \multicolumn{2}{|l|}{$900^{\circ} \mathrm{C}$} \\
\hline & $21,6 \mathrm{Mpa}$ & $32,96 \mathrm{Mpa}$ & $21,6 \mathrm{Mpa}$ & $32,96 \mathrm{Mpa}$ & $21,6 \mathrm{Mpa}$ & $32,96 \mathrm{Mpa}$ \\
\hline $3 \mathrm{jam}$ & $64,92 \%$ & $65 \%$ & $37,7 \%$ & $31,55 \%$ & $21,64 \%$ & $18,03 \%$ \\
\hline $5 \mathrm{jam}$ & $63,93 \%$ & $64,38 \%$ & $36,4 \%$ & $24,46 \%$ & $20,33 \%$ & $16,74 \%$ \\
\hline $7 \mathrm{jam}$ & $62,6 \%$ & $63 \%$ & $25,57 \%$ & $19,96 \%$ & $16,06 \%$ & $14,16 \%$ \\
\hline
\end{tabular}

Selain itu menurut Suhendro (2000) apabila beton dipanasi pada suhu sekitar $200^{\circ} \mathrm{C}$, kekuatannya tampak sedikit meningkat karena pada suhu diatas $100^{\circ} \mathrm{C}$ air bebas yang terserap beton menguap, selanjutnya ketika jauh diatas $100^{\circ} \mathrm{C}$ air semen secara kimiawi dalam dalam beton juga menguap. Selanjutnya panas dinaikkan lagi kekuatan beton menurun. Pada suhu antara $400^{\circ} \mathrm{C}$ sampai $600^{\circ} \mathrm{C}$ kalsium hidroksida $(\mathrm{Ca}(\mathrm{OH}) 2)$ berubah komposisi menjadi kalsium oksida $(\mathrm{CaO})$ yang sama sekali tidak mempunyai kekuatan. Selanjutnya diatas suhu $600^{\circ} \mathrm{C}$ atau 700C unsur hasil hidrasi yang lain berubah komposisi sehingga kekuatan beton kehilangan kekuatan sama sekali, sebagaimana tampak pada Gambar 1 di bawah ini:

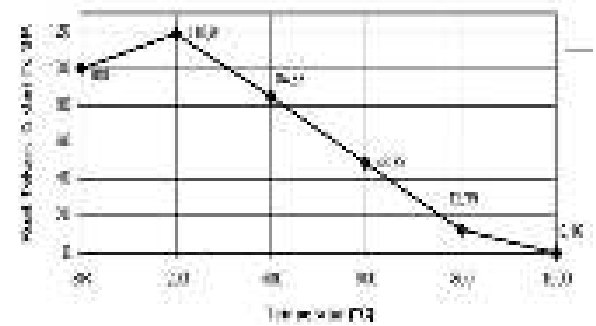

Gambar 1. Degradasi kuat tekan beton pada berbagai temperatur (Suhendro,2000) 
Kebakaran yang terjadi pada sebuah bangunan, tidak hanya beton yang mengalami penurunan kuat tekan tetapi ada material lain yang perlu dipertimbangkan kekuatannya. Menurut Santosa. A (2009) baja tulangan yang dipanasi pada suhu $600^{\circ} \mathrm{C}$ dan $900^{\circ} \mathrm{C}$ mengalami penurunan kuat lelehnya. Adapun penurunan baja tulangan berturut-turut dapat dilihat pada Tabel 2.

Tabel 2. Penurunan Kekuatan Sisa Mutu Baja Tulangan

\begin{tabular}{|c|c|c|c|c|c|}
\hline $\begin{array}{ll}\text { No } & \text { Benda } \\
\text { Uji } & \end{array}$ & Suhu $\left({ }^{\circ} \mathrm{C}\right)$ & $\begin{array}{l}\text { Selimut } \\
\text { Beton }\end{array}$ & $\begin{array}{l}\text { Tegangan } \\
\text { Leleh } \\
(\mathrm{Mpa}) \\
\end{array}$ & Rata-Rata & $\begin{array}{l}\text { Presentasi } \\
\text { penurunan } \\
(\%)\end{array}$ \\
\hline A & 0 & $4 \mathrm{~cm}$ & 388 & 386 & 0 \\
\hline 1 & 600 & $2 \mathrm{~cm}$ & 374,4 & \multirow{3}{*}{385,25} & \multirow{3}{*}{0,3} \\
\hline 2 & 600 & $2 \mathrm{~cm}$ & 388,82 & & \\
\hline 3 & 600 & $2 \mathrm{~cm}$ & 392,74 & & \\
\hline 1 & 600 & $4 \mathrm{~cm}$ & 382,91 & \multirow{3}{*}{382,5} & \multirow{3}{*}{1} \\
\hline 2 & 600 & $4 \mathrm{~cm}$ & 385,65 & & \\
\hline 3 & 600 & $4 \mathrm{~cm}$ & 378,94 & & \\
\hline 1 & 900 & $2 \mathrm{~cm}$ & 374,11 & \multirow{3}{*}{374,97} & \multirow{3}{*}{2,5} \\
\hline 2 & 900 & $2 \mathrm{~cm}$ & 366,87 & & \\
\hline 3 & 900 & $2 \mathrm{~cm}$ & 383,93 & & \\
\hline 1 & 900 & $4 \mathrm{~cm}$ & 381,15 & \multirow{3}{*}{377,48} & \multirow{3}{*}{2} \\
\hline 2 & 900 & $4 \mathrm{~cm}$ & 360,48 & & \\
\hline 3 & 900 & $4 \mathrm{~cm}$ & 390,81 & & \\
\hline
\end{tabular}

\section{METODE PENELITIAN}

Adapun metode penelitian yang digunakan dalam Penelitian adalah sebagai berikut :

a. Tahap Pengumpulan Data :

Nama bangunan : Kantor Pegawai PLN

Lokasi bangunan : Madiun

Fungsi : Perkantoran

Jumlah lantai : 2 Lantai

Tinggi setiap lantai: $3,57 \mathrm{~m}$

b. Preliminary Design

Desain Gedung direncanakan sebagai berikut :

Dimensi Balok 1 (B1) : 300x500 mm

Balok 2 (B2) : 400x400 mm

Tebal pelat $: 120 \mathrm{~mm}$

Kelas situs gempa : kelas D pada wilayah gempa Indonesia

Mutu Beton (fc') : 25 Mpa(Setara dengan K300)

Mutu Baja tulangan utama ulir (fy): $400 \mathrm{Mpa}$

Mutu Baja tulangan sengkang (fy): $240 \mathrm{Mpa}$

Mutu material profil baja BJ 41

Mutu material baut angkur (dynabolt) tipe HSL-3 dari hilti :

$$
\begin{array}{ll}
\mathrm{Fy} & =640 \mathrm{Mpa} \\
\mathrm{Fu} & =800 \mathrm{Mpa}
\end{array}
$$

Perencanaan Balok :

Dalam perhitungan momen nominal balok terdapat 2 kondisi:

- Kondisi 1, bila garis netral berada pada posisi flens (sayap) $\mathrm{c}<\mathrm{hf}$, maka analisis penampang dapat dianggap sebagai balok persegi dengan lebar balok sama dengan efektif balok (be). Kondisi 1 dijelaskan pada diagram yang terdapat pada Gambar 2.

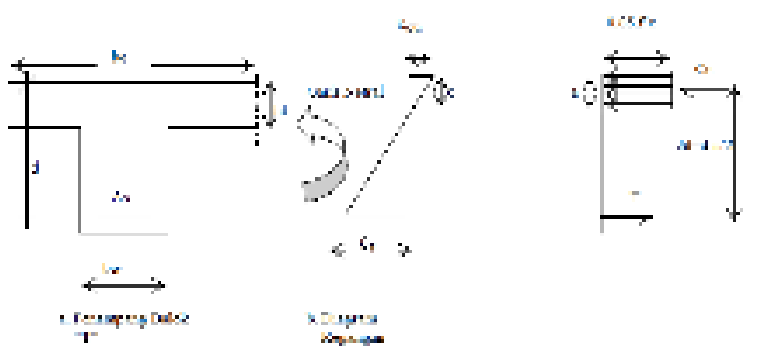

Gambar 2. Diagram Tegangan Regangan Balok Bersayap Kondisi 1

- Kondisi 2, bila garis netral memotong badan, c > hf maka balok diperlakukan sebagai balok $\mathrm{T}$ murni.

Kuat lentur nominal yang dihitung berdasarkan distribusi teganganplastis dapat dikategorikan menjadi dua kasus sebagai berikut: Sumbu netral plastis jatuh pada pelat beton, dengan mengacu pada diagram yang terdapat pada Gambar 3 .
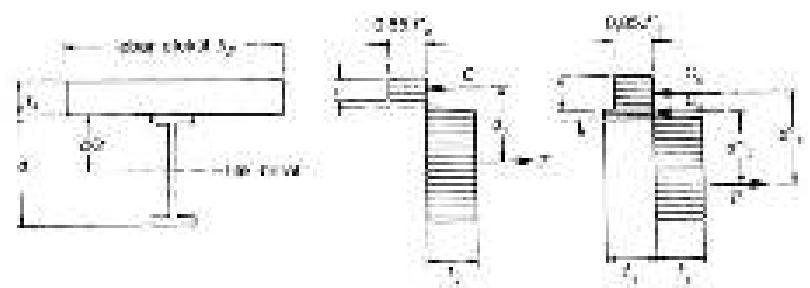

Gambar 3. Kuat Lentur Nominal

Berdasarkan Distribusi Tegangan Plastis :

a. Sumbu netral jatuh pada beton

b. Sumbu netral plastis jatuh pada profil baja

c. Permodelan Struktur

Permodelan Bangunan yang digunakan untuk penelitian menggunakan bantuan program SAP 2000 .

d. Pembebanan Struktur

Pembebanan merupakan faktor penting dalam perencanaan dan identifikasi struktur. Sebagai asumsi dasar gaya-gaya dan beban yang bekerja pada struktur diperlukan pembebanan pada bangunan yang dimodelkan. Secara umum, struktur bangunan dikatakan aman dan stabil apabila mampu menahan beban gravitasi (beban mati dan beban hidup), beban gempa, maupun beban angin yang bekerja pada bangunan tersebut.

Pada perencaan suatu bangunan beban yang diterima oleh struktur berbeda-beda tergantung pada desian bangunannya. Menurut Peraturan Pembebanan Indonesia Untuk Gedung (1983) terdapat beberapa pembebanan yang digunakan untuk merencanakan struktur yaitu beban mati, beban hidup, beban gempa, dan lain-lain. 
Adapun rincian pembebanan pada struktur yang direncanakan adalah sebagai berikut :

1. Beban Mati

Beban mati non struktural sesuai dengan PBI 1983 meliputi Berat Lantai Tegel, Spesi, Plumbing, Plafon+Penggantung, dan Ducting AC+Pipa

2. Beban Hidup

Beban hidup sesuai dengan PBI 1983 pada pelat lantai perkantoran adalah $250 \mathrm{~kg} / \mathrm{m} 2$.

3. Beban Gempa

Pada perencanaan struktur bangunan yang memiliki ketahanan terhadap beban gempa harus disesuaikan dengan SNI-1726-2012 menggunakan renpons spektrum wilayah gempa kelas situs D dengan asumsi tanah sedang.

Supaya komponen struktur memenuhi kriteria persyaratan kekuatan maka beban-beban diatas harus dikombinasikan. Sesuai SNI-1726-2012 pasal 4.2.2 kombinasi bebannya sebagai berikut:

- $\mathrm{U}=1,4 \mathrm{D}$

- $\mathrm{U}=1,2 \mathrm{D}+1,6 \mathrm{~L}+0,5(\mathrm{~A}$ atau $\mathrm{R})$

- $\mathrm{U}=1,2 \mathrm{D}+1,0 \mathrm{~L} \pm 1,6 \mathrm{~W}+0,5$ (A atau $\mathrm{R})$

- $\mathrm{U}=0,9 \mathrm{D} \pm 1,6 \mathrm{~W}$

- $\mathrm{U}=1,2 \mathrm{D}+1,0 \mathrm{~L} \pm 1,0 \mathrm{E}$

- $\mathrm{U}=0,9 \mathrm{D} \pm 1,0 \mathrm{E}$

e. Analisa Momen Nominal Balok Sebelum dan Pasca Kebakaran.

Pada perhitungan momen nominal dan geser balok terdapat dua kondisi yang harus dihitung yaitu : sebelum kebakaran dan sesudah kebakaran.

Pada perhitungan momen nominal gambar detail tulangan dapat dilihat pada lampiran 1, adapaun langkah-langkah perhitungan sebagai berikut:

1. Menetukan lebar efektif balok

2. Menghitung a, zona tekan diasumsikan berbentuk persegi.

- Momen Nominal Balok Komposit

Pada analisis struktur yang telah dilakukan sebelumnya pada balok B1 mengalami kondisi tidak aman karena momen nominal < momen ultimate maka struktur memerlukan perkuatan dengan menggunakan profil siku. Pada perencanaan ini profil siku menggunakan cara coba-coba sampai menenukan profil yang efisien Adapun perencanaan perkuatan struktur dengan penambahan profil siku seperti pada Gambar 4, untuk diagram distribusi Tegangan dan

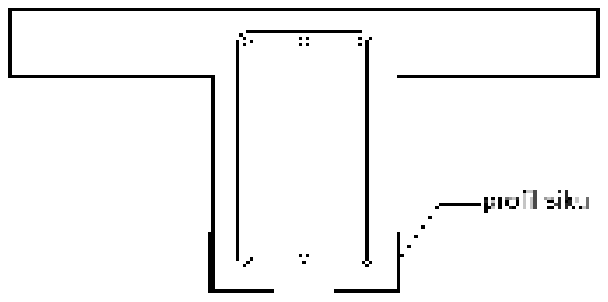

Gambar 4. Perkuatan Struktur Balok 1 Dengan Penambahan Profil Siku.

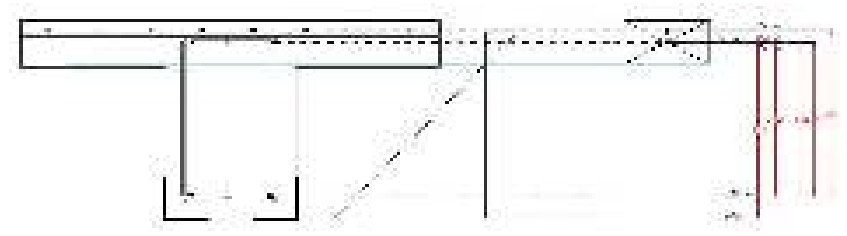

Gambar 5. Distribusi Tegangan dan Regangan Balok Komposit Interior.

f. Analisa Momen Nominal Balok Komposit Digunakan Profil Siku 70x70x7 dan Profil Siku $65 \times 65 \times 7$. Detail pemasangan Profil Siku Balok seperti pada Gambar 6.

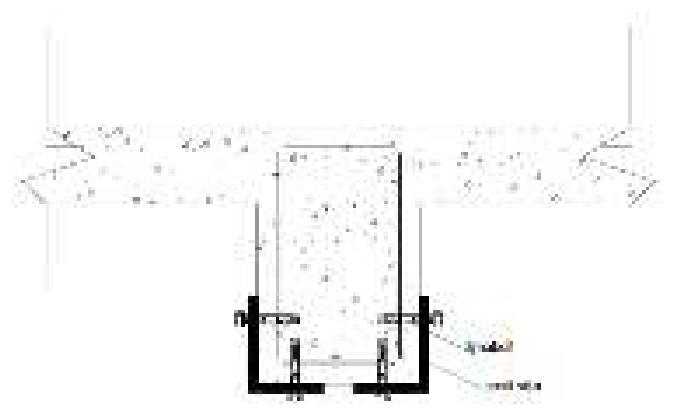

Gambar 6. Pemasangan Profil Siku Balok.

\section{HASIL PENELITIAN}

a. Permodelan Struktur

Data lapangan pada penelitian ini adalah gedung PLN Madiun di Jalan M.T. Haryono, Kota Madiun, Jawa Timur. Gambar pemodelan struktur menggunakan bantuan Program SAP 2000 dapat dilihat pada Gambar 7. 
Pada hasil Tabel 3 sampai Tabel 6 menunjukan

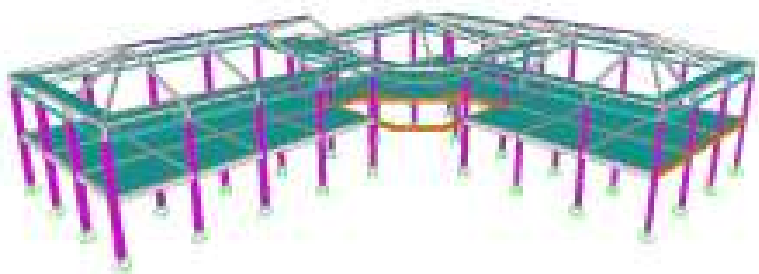

Gambar 7. Permodelan Struktur Kantor PLN Madiun

b. Hasil Analisa Momen Nominal Balok Sebelum dan Pasca Kebakaran.

Setelah dilakukan permodelan, maka dilakukan perhitungan tulangan dan perhitungan momen nominal pada Balok, hasil perhitungan momen nominal sebelum kebakaran terdapat pada Tabel 3.

Tabel 3. Momen Nominal Sebelum Kebakaran.

\begin{tabular}{|l|l|l|l|l|l|}
\hline $\begin{array}{l}\text { Nama } \\
\text { Balok }\end{array}$ & Lokasi & Perletakan & Mu (kg.m) & $M n \times \phi$ & Ket \\
\hline Balok 1 & Eksterior & Tumpuan & 8231 & 8311,3 & oke \\
\hline & & Lapangan & 4108,26 & 8311,3 & oke \\
\hline & Interior & Tumpuan & 8096,41 & 8471 & oke \\
\hline & & Lapangan & 4260,94 & 8471 & oke \\
\hline Balok2 & Eksterior & Tumpuan & 9167,05 & 11243,96 & oke \\
\hline & & Lapangan & 4286,97 & 8311,3 & oke \\
\hline & Interior & Tumpuan & 8064,16 & 11243,96 & oke \\
\hline & & Lapangan & 4373,76 & 8471 & oke \\
\hline
\end{tabular}

Tabel 4. Momen Nominal Pada Balok Pasca Kebakaran Dengan Fc' Sisa $65 \%$ Pada Suhu $300^{\circ} \mathrm{C}$ dengan Durasi 3 Jam.

\begin{tabular}{|l|l|l|l|l|l|}
\hline $\begin{array}{l}\text { Nama } \\
\text { Balok }\end{array}$ & Lokasi & Perletakan & Mu (kg.m) & $\begin{array}{l}M n \times \phi \\
(\mathrm{kg} . \mathrm{m})\end{array}$ & Ket \\
\hline Balok 1 & Eksterior & Tumpuan & 8231 & 8163,89 & Tidak oke \\
\hline & & Lapangan & 4108,26 & 8263,89 & oke \\
\hline & Interior & Tumpuan & 8096,41 & 8409 & oke \\
\hline & & Lapangan & 4260,94 & 8409 & oke \\
\hline Balok 2 & Eksterior & Tumpuan & 9167,05 & 11134,81 & oke \\
\hline & & Lapangan & 4286,97 & 8163,89 & oke \\
\hline & Interior & Tumpuan & 8064,16 & 11134,81 & oke \\
\hline & & Lapangan & 4373,76 & 8409 & oke \\
\hline
\end{tabular}

Tabel 5. Momen Nominal Pada Balok Pasca Kebakaran Pada Suhu $600^{\circ} \mathrm{C}$ fc' Sisa $34 \%$ dengan Durasi 3 Jam dan fy Sisa $99 \%$ dengan Durasi 2 Jam.

\begin{tabular}{|l|l|l|l|l|l|}
\hline $\begin{array}{l}\text { Nama } \\
\text { balok }\end{array}$ & Lokasi & Perletakan & Mu (kg.m) & $\begin{array}{l}M n \times \phi \\
(\mathrm{kg} . \mathrm{m})\end{array}$ & Ket \\
\hline Balok1 & Eksterior & Tumpuan & 8231 & 7780,1 & Tidak oke \\
\hline & & Lapangan & 4108,26 & 7780,1 & oke \\
\hline & Interior & Tumpuan & 8096,41 & 8249,6 & oke \\
\hline & & Lapangan & 4260,94 & 8249,6 & oke \\
\hline Balok2 & Eksterior & Tumpuan & 9167,05 & 10747,85 & oke \\
\hline & & Lapangan & 4286,97 & 7780,1 & oke \\
\hline & Interior & Tumpuan & 8064,16 & 10747,85 & oke \\
\hline & & Lapangan & 4373,76 & 8249,6 & oke \\
\hline
\end{tabular}
bahwa balok 1 maupun balok 2 sebelum kebakaran kapasitas kekuatannya memenuhi syarat karena $\mathrm{Mu}$ $\leq \phi \times M n$ seperti pada Tabel 3. Kemudian setelah kebakaran balok 1 dan balok 2 mengalami penurunan kapasitas kekuatan tetapi masih dalam kondisi aman seperti pada Tabel 4 sedangkan pada suhu $600^{\circ} \mathrm{C}$ mengalami perlemahan kekuatan sampai batas tidak aman pada balok 1 eksterior seperti pada Tabel 5. Selanjutnya pada suhu $900^{\circ} \mathrm{C}$ dengan durusi kebakaran 3 jam pada balok dan 2 jam pada baja tulangan seperti pada Tabel 6 interior maupun eksterior mengalami penurunan kapasitas kekuatannya sehingga tidak mampu menahan beban bangunan kareana nilai $\mathrm{Mu} \geq \phi \times M n$.

Tabel 6. Momen Nominal Pada Balok Pasca Kebakaran Pada Suhu $900^{\circ} \mathrm{C}$ fc' Sisa $21 \%$ dengan Durasi 3 Jam dan fy Sisa 98\% Durasi 2 Jam.

\begin{tabular}{|l|l|l|l|l|l|}
\hline $\begin{array}{l}\text { Nama } \\
\text { Balok }\end{array}$ & Lokasi & Perletakan & Mu (kg.m) & $\begin{array}{l}M n \times \phi \\
(\text { kg.m) }\end{array}$ & Ket \\
\hline Balok 1 & Eksterior & Tumpuan & 8231 & 7161,7 & Tidak oke \\
\hline & & Lapangan & 4108,26 & 7161,7 & oke \\
\hline & Interior & Tumpuan & 8096,41 & 7891,8 & Tidak oke \\
\hline & & Lapangan & 4260,94 & 7891,8 & oke \\
\hline Balok 2 & Eksterior & Tumpuan & 9167,05 & 10280,6 & oke \\
\hline & & Lapangan & 4286,97 & 7161,7 & oke \\
\hline & Interior & Tumpuan & 8064,16 & 10280,6 & oke \\
\hline & & Lapangan & 4373,76 & 7891,8 & oke \\
\hline
\end{tabular}

c. Hasil Analisa Momen Nominal Balok Komposit

Pada analisis struktur yang telah dilakukan pada balok B1 mengalami kondisi tidak aman karena momen nominal $<$ momen ultimate maka struktur memerlukan perkuatan dengan menggunakan profil siku. Pada perencanaan ini profil siku menggunakan cara coba-coba sampai menemukan profil yang efisien Adapun perencanaan perkuatan struktur dengan penambahan profil siku dengan cara mencari Tegangan Beton, kemudian menghitung Momen Nominal, dan divalidasi menggunakan bantuan Program SAP 2000. Hasil yang didapat terdapat pada Tabel 7 dan Tabel 8.

Tabel 7. Momen Nominal Pada Balok 1 Komposit Berdasarkan Berbagai Variasi Profil Siku.

\begin{tabular}{|c|l|l|l|l|l|}
\hline No & Balok & $\begin{array}{l}\text { Profil Siku } \\
(\mathrm{mm})\end{array}$ & $\begin{array}{l}\text { Mu } \\
(\mathrm{N} . \mathrm{mm})\end{array}$ & $\begin{array}{l}\text { Mn } \\
(\mathrm{N} . \mathrm{mm})\end{array}$ & Ket \\
\hline 1 & $\begin{array}{l}\text { Balok } \\
(300 \times 500)\end{array}$ & $70 \times 70 \times 7$ & 80964100 & 253602548 & Oke \\
\hline 2 & $\begin{array}{l}\text { Balok } \\
(300 \times 500)\end{array}$ & $65 \times 65 \times 7$ & 80964100 & 249270367 & Oke \\
\hline
\end{tabular}

Tabel 8. Momen Nominal Pada Balok 2 Komposit Berdasarkan Berbagai Variasi Profil Siku.

\begin{tabular}{|c|l|l|l|l|l|}
\hline No & Balok & $\begin{array}{l}\text { Profil Siku } \\
(\mathrm{mm})\end{array}$ & $\begin{array}{l}\text { Mu } \\
(\mathrm{N} . \mathrm{mm})\end{array}$ & $\begin{array}{l}\text { Mn } \\
(\text { N.mm })\end{array}$ & Ket \\
\hline 1 & $\begin{array}{l}\text { Balok } \\
(400 \times 400)\end{array}$ & $70 \times 70 \times 7$ & 82310000 & 169042379 & Oke \\
\hline 2 & $\begin{array}{l}\text { Balok } \\
(400 \times 400)\end{array}$ & $65 \times 65 \times 7$ & 80964100 & 164494928 & Oke \\
\hline
\end{tabular}



d. Perhitungan Balok Komposit dengan Variasi Regangan Beton ( $E \mathrm{cu})$

Pada perhitungan balok komposit dengan variasi regangan beton (Ecu) ada dua kondisi yaitu dengan perhitungan manual dan perhitungan dengan bantuan dengan progam SAP200 digunakan untuk mencari variasi momen yang dihasilkan oleh variasi regangan Balok Eksterior dan Interior terdapat pada Grafik pada Gambar 8 dan Gambar 9.

\section{- Balok Komposit Eksterior}

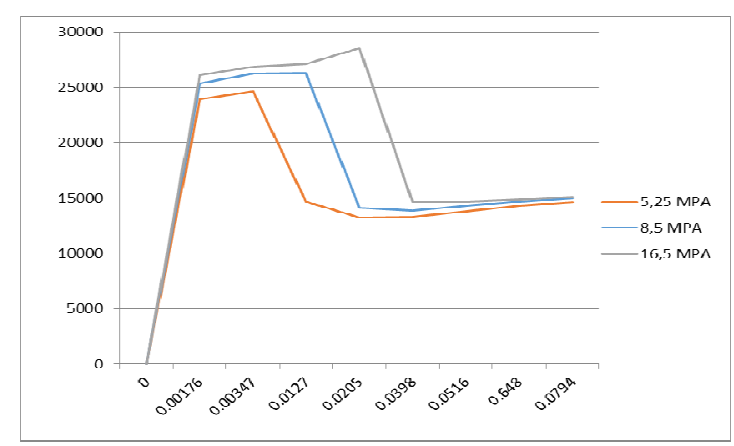

Gambar 8. Grafik Variasi Regangan Beton Dan Dan Mutu Beton Pasca Kebakaran Pada Balok Eksterior

- Balok Komposit Interior

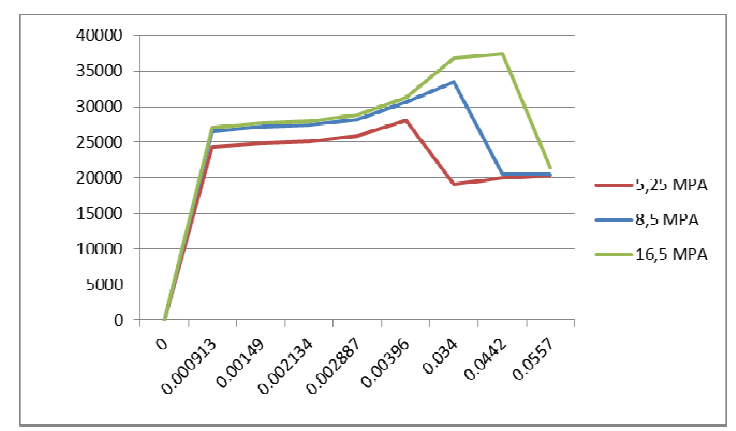

Gambar 9. Grafik Variasi Regangan Beton Dan Dan Mutu Beton Pasca Kebakaran Pada Balok Interior

\section{KESIMPULAN}

Dari hasil analisa didapatkan kesimpulan sebagai berikut :

a. Balok yang mengalami kebakaran pada suhu $900^{\circ} \mathrm{C}$ dengan durasi kebakaran 3 jam pada beton dan 2 jam pada baja tulangan mengalami perlemahan struktur sehingga ada balok yang mengalami kondisi yang tidak aman.

b. Profil siku yang digunakan L65x65x7.

c. Momen nominal balok setelah penambahan Profil siku L65x65x7 adalah :

$\mathrm{Mn}=24927.04 \mathrm{~kg} . \mathrm{m}$ pada balok interior dan $\mathrm{Mn}=16449.49 \mathrm{~kg} . \mathrm{m}$ pada eksterior.

d. Prosentasi penurunan kekuatan struktur pasca kebakaran sebagai berikut :
- $\quad$ Pada pelat $2,18 \%$ pada suhu $300^{\circ} \mathrm{C}$ dan $8,72 \%$ pada suhu $600^{\circ} \mathrm{C}$.

- Pada balok balok 1 prosentasi penurunan sebesaar $1,77 \%$ dan balok 2 sebesar $1 \%$ pada suhu $300^{\circ} \mathrm{C}$.

- Pada suhu $600^{\circ} \mathrm{C}$ Pada balok balok 1 prosentasi penurunan sebesaar $6,39 \%$ dan balok 2 sebesar $3,2 \%$.

- $\quad$ Pada suhu $900^{\circ} \mathrm{C}$ prosentase penurunan kekuatan struktur $13,83 \%$ pada balok 1 dan balok 2 sebesar $8,57 \%$.

\section{DAFTAR PUSTAKA}

Ahmad, dkk. 2006. Tinjuan Kelayakan Forensik Engineering Dalam Menganalisis Kekuatan Sisa Bangunan Pasca Kebakaran. Makasar : Laporan Penelitian Dosen Muda Jurusan Sipil Dan Perencanaan Fakultas Teknik - Universitas Negeri Makasar.

Bayuasri T, dkk. 2006. Perubahan Perilaku Mekanis Beton Akibat Temperatur Tinggi. Semarang : Laporan Tugas Akhir Magister Teknik Sipil - Universitas Diponegoro.

Dinas Penanggulangan Kebakaran dan Penyelamatan Provinsi DKI Jakarta. 2017. Statistik Kebakaran Berdasarkan Penyebab.

Priyosulistyo, H. 2002. Teknologi Beton Pasca Kebakaran. Yogyakarta : Prosiding Seminar Nasional Teknologi Beton Dan Software Untuk Perencanaan Bangunan Sipil, Pusat Studi Ilmu Teknik-Universitas Gajah Mada.

Suhendro, B. 2000. Analisis Degradasi Kekuatan Struktur Beton Bertulang Pasca Kebakaran. Yogyakarta : Makalah - Universitas Gajah Mada.

Tjokrodimulyo K. 2000. Pengujian Mekanik Laboratorium Beton Pasca Bakar. Yogyakarta.

Turnip, J. M. 2014. Perkuatan Struktur Beton Bertulang Pasca Kebakaran (Studi Kasus Gedung Fakultas Matematika Dan Ilmu Pengetahuan Alam Universitas Sumatera Utara). Medan : Laporan Tugas Akhir Progam Studi Teknik Sipil - Universitas Sumatera Utara.

Wiyono D, R dan Trisina W. 2013. Analisis Lendutan Seketika Dan Lendutan Jangka Panjang Pada Struktur Balok. Bandung: Jurnal Teknik Sipil. Vol. 14 (1) :1-83. 
Jurnal Rekayasa Tenik Sipil Universitas Madura Vol. 2 No.1 Juni 2019 ISSN 2527-5542

\section{Halaman Ini Sengaja Dikosongkan}

